\title{
Analysis of the application of ecological niche modeling in phylogeographic studies: contributions, challenges, and future
}

\author{
Carlos Luna-Aranguré1, 2*, and Ella Vázquez-Dominguez'
}

\begin{abstract}
1 Departamento de Ecología de la Biodiversidad, Instituto de Ecología, Universidad Nacional Autónoma de México, Ciudad Universitaria, 04510, Ciudad de México, México. Email: carlos luna55@hotmail.com (CL-A), evazquez@ecologia.unam.mx (EV-D)

2 Posgrado en Ciencias Biológicas, Universidad Nacional Autónoma de México, Edificio D, 1 er Piso, Unidad de Posgrado, 04510, Ciudad de México,, México.

*Corresponding author
\end{abstract}

\begin{abstract}
The combined application of ecological niche modeling in phylogeographic studies has contributed to better understanding the relationship between the patterns of genetic variation of species and the abiotic conditions where their populations have evolved. This has allowed broadening and strengthening the spectrum of phylogeographic questions and hypotheses to be tested, based on the increasing availability of data, algorithms, and models. However, when these two approaches are combined, some of their limitations are also added, despite taking advantage of their strengths. This review explores some of the latest contributions of this application. We found that $44 \%$ of the studies reviewed address the effect of the environment on the diversification and structure of lineages; $20 \%$ of the models concern mammals and 27 $\%$, reptiles; and $34 \%$ of the articles addressed the biota of the Nearctic region. This review also explores the most important challenges and future perspectives resulting from this synergy.

La aplicación del modelado de nicho ecológico en estudios de filogeografía ha contribuido a entender la relación entre los patrones de variación genética de las especies y las condiciones abióticas en las que sus poblaciones se han diferenciado. Esta aplicación ha permitido ampliar y robustecer el espectro de preguntas e hipótesis filogeográficas a probar, apoyándose en la creciente disponibilidad de datos, algoritmos y modelos. Sin embargo, al combinar estos dos métodos, aún cuando se aprovechan sus fortalezas, es inevitable que también se sumen varias de sus limitantes. En esta revisión exploramos puntualmente algunas de las contribuciones más recientes de esta aplicación, encontrando que el $44 \%$ de los estudios se enfocan en explorar el efecto del ambiente en la diversificación y estructura de los linajes, mientras que el $20 \%$ de los modelos de estudio son mamíferos y $27 \%$ reptiles, donde 34 \% de los artículos se concentran en biota de la región Neártica. Asimismo, esta revisión explora los desafíos más importantes y las perspectivas a futuro que resultan de esta sinergia.
\end{abstract}

Key words: ecological niche; lineage divergence; niche conservatism; niche modeling; phylogeography; potential distribution.

(C) 2020 Asociación Mexicana de Mastozoología, www.mastozoologiamexicana.org

\section{Introduction}

Understanding the relationship between geography, the distribution of species, and the patterns of species differentiation is a core element in the study of evolutionary biology (Avise 2000). Merging the knowledge about each of these aspects requires a unifying approach, where phylogeography is an integrating discipline that articulates information about the genetic structure, geographic distribution, and genealogy of natural populations (Avise 2000; VázquezDomínguez 2007). As such, phylogeography is a converging ground for various approaches to study biodiversity.

Taking into consideration the abiotic variables associated with geography is essential in phylogeography, given their influence in processes such as isolation, divergence and, eventually, speciation (Kozak et al. 2008). These scenopoetic variables are also the backbone of ecological niche modeling (Peterson et al. 2011), defined as the set of methods and techniques to assess the variables in the environment of living organisms, and how these variables are associated with the geographic distribution of organisms (Carstens and Richards 2007). Based on statistical or mechanistic approaches, ecological niche modeling (ENM) opens the possibility to explore the existing relationships between organisms and environmental conditions, by evaluating the drivers governing the occurrence of species in time and space (Svenning et al. 2011).

In parallel with the ongoing development of new ENM methods, there is a growing availability of large species distribution databases generated from geographic information systems, such as topological, climatic, oceanographic, and geological models (Varela et al. 2011). For this reason, ENM aims to identify and quantify the relationship between environmental factors and the distribution of populations at different scales, i. e., to characterize and measure their ecological niche (Soberón 2007).

How do we define niche? The term "niche" is described in multiple ways in the literature. One of the earliest definitions is attributed to Grinnell (1917), who defined it as the climatic and environmental conditions required by a species in order to survive, along with the morpho-physiological and behavioral characteristics of the species that allow it to interact with the environment. For Elton (1927), the niche of an animal species is its place in the biotic environment, i. e., its relationships with food and enemies, while Hutchinson 
(1957) defines it as the ' $n$-dimensional' hyper-volume where the dimensions are environmental conditions and resources defining the requirements of an individual or a species in order to survive and maintain its populations. The contribution of the $n$-dimensional concept of Hutchinson is a cornerstone in the conceptual relationship of the ecological niche of a species and its geographic distribution. Thus, Grinnell's niche concept is based on climatic conditions operating at a large spatial scale; the Eltonian niche refers to fine-scale variables that can be either consumed or modified by a species, and the Hutchinsonian niche can include all sorts of relevant variables for the species, expressed at both fine and large spatial scales (Soberón 2007).

Within the conceptual framework of the ecological niche, Soberón and Peterson (2005) point out four classes of factors that define the distribution of species: 1) abiotic conditions, such as climate and physical environment; 2) biotic factors, including the interactions with other organisms that modify the ability of a species to maintain its populations; 3) accessibility of the species to new areas, given its dispersal capability; 4) evolutionary capacity of populations to adapt to new conditions. These factors interact to various degrees over time and at different spatial scales to produce the complex geographic distribution of a species, whose understanding is essential for phylogeography.

The study of the ecological niche is based on two key elements; first, niche conservatism, defined as the evolutionary patterns within which species tend to share their ecological requirements with their ancestors (Wiens and Graham 2005). This results in two or more closely related species that are ecologically more similar than what would be expected according to their phylogenetic relationships (Losos 2008). Its counterpart is niche evolution (or niche divergence), which refers to the persistence and adaptation of populations to new environmental conditions (Holt 2014). It should be noted that although multiple studies integrating ENM to evolutionary aspects seek to discern between these two hypotheses, the drivers of niche evolution are still unknown (Holt 2014). For this reason, niche evolution assessment is currently an ongoing area of research.

What is phylogeography? Phylogeography works with the historical components of the spatial distribution of gene lineages, with time and space as core pillars. Avise (2000) defines it as "... the field of study concerned with the principles and processes governing the geographic distributions of genealogical lineages, especially those within and among closely related species". It involves the assessment of the genetic structure, distribution, and differentiation within and among natural populations throughout their distribution range, using molecular markers like DNA sequences. Another characteristic is the ability to estimate the lineages' age and the time of divergence between them, based on the diversification rate of the molecular marker used. The study of the geographic distribution of lineages has made it possible to describe historical events, including habitat fragmentation, expansion of the distribution range of species and populations, vicariance, migration and extinction events, as well as other spatial and temporal processes affecting population structure or promoting speciation. Indeed, Hardy et al. (2002) have documented consistent patterns in species, showing that these processes have been significant drivers in the diversification of lineages. Environmental factors like climate, and intrinsic factors including dispersal ability and ecological characteristics, have also played a key role (Vázquez-Domínguez 2007).

\section{Material and methods}

Literature assessment. This review considered articles that met three criteria: 1) inclusion of "Phylogeography" and "Niche modeling" as key words; 2) published between 2007 and July 2019; and 3) studies that specifically reflect the combined or integrating application of phylogeographic analyses and ecological niche modeling. We identified a total of 29 articles. The results showed that $44 \%$ of these studies explore the effect of the environment on the differentiation and structuring of lineages, followed by $23 \%$ that assess the effect of historical environmental changes on phylogeographic patterns in the groups studied; only 3 $\%$ addressed the integrative application of these methods for the assessment of species extinction risk (Figure 1a). On the other hand, $20 \%$ of study models focus on mammals, $27 \%$ on reptiles, $20 \%$ on arthropods, and $10 \%$ on amphibians (Figure 1b). Importantly, $34 \%$ of the articles focused on components of the biota of the Nearctic region, $24 \%$ on the Palearctic, and $18 \%$ on the Neotropical (Figure 1c).

\section{Results}

The best of both worlds: the state of the art. The application of ENM to phylogeographic studies has contributed to assess the abiotic factors that govern the evolutionary history of the lineages structuring a species, jointly with the ecological-environmental factors structuring the genetic variation of species across their range and the landscape (Figure 2). It has also enabled exploring how these factors are associated with the lineages' divergence (Alvarado-Serrano and Knowles 2014; Suárez-Atilano et al. 2017). A relevant example of this application within a macroevolutionary framework is the theoretical study of Rangel et al. (2018), who used simulations of processes that shape the biota's geographic and evolutionary patterns (birds, mammals, and plants) of South America, and compared the climate simulations and models for the past 800,000 years with empirical speciation, biodiversity, and lineage extinction data. Their results suggest that climatic heterogeneity and topography have governed their evolutionary and diversification patterns. On the other hand, Mizerovska et al. (2019) evaluated the influence of changes in climate, topography, and rivers during the PlioPleistocene on the diversification of African rodents of the Praomys jacksoni complex. The results confirmed that the evolutionary history of the complex (five lineages) is associated with Pleistocene changes and diversification of the refugia represented by forested areas. 


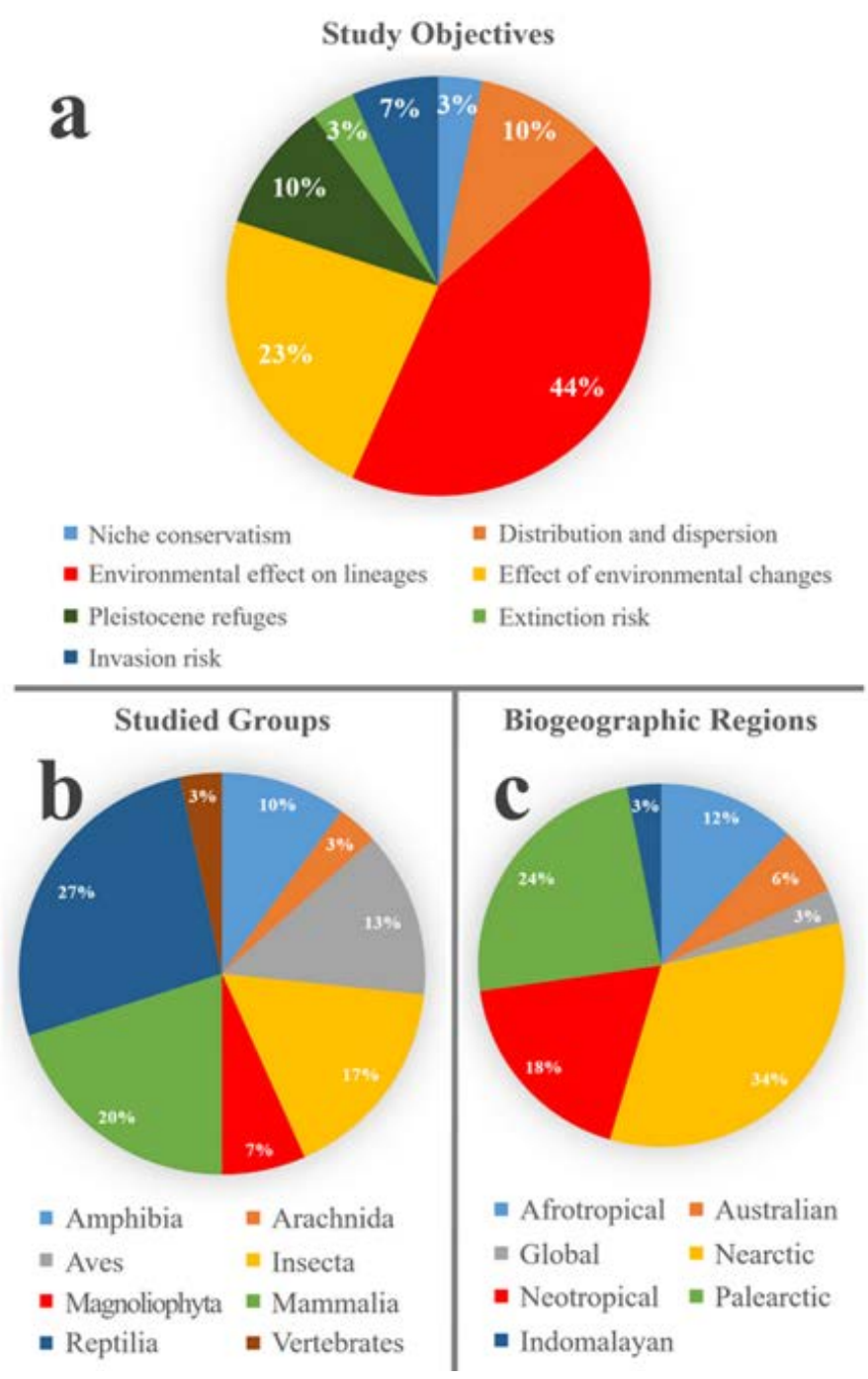

Figure 1. Graphs of the 29 studies reviewed in this study, broken down by percentages of a) objectives, b) biological groups studied, c) biogeographical regions where those studies were carried out.

Recently, the temporal focus of phylogeographic and niche studies has broadened, exploring both historical and current geographic patterns to produce ecological projections of past and future distributions. For instance, Martínez-Méndez et al. (2015) integrated analyses of evolutionary history, contemporary geographic distribution, and future distribution projections for the lizard Sceloporus serrifer, and concluded that populations inhabiting the lowest lands will become extinct before the year 2070. This approach has also been used to explore diversification patterns considering taxonomic categories (species, subspecies, etc.) as well as evolutionary lineages at the population level (de Queiroz 2007). For example, Smith et al. (2018) suggest that the building niche models to investigate lineages sheds light about the role of the environment in local adaptation and phylogeographic structuring patterns (e. g. Suárez-Atilano et al. 2017; these models also emphasize the importance of incorporating information regarding phylogeny and evolutionary models into ENM strategies. Therefore, a great variety of questions have been raised, as methods are continually emerging for the integrative use of ENM and phylogeography, which are summarized below. It should be noted that while Therya is a publication about mammals, the number of studies within the scope of interest in this review and on mammals is so limited that we also describe relevant examples related to other taxa.

\section{Discussion}

Applications of the combined use of ENM and phylogeography. One of the earliest studies where ENM was applied to phylogeography is the investigation of Hugall et al. (2002), involving an approach that compared paleodistribution models with phylogeographic information for a snail endemic to tropical forests in northern Australia. They established the location of historical refugia and contributed to the understanding of species expansion patterns from these refugia.

This approach gained popularity in the decade that followed and was used to address questions regarding the distribution and dispersal of species in relation to their genetic variation patterns. Some studies have focused on species with restricted ecological requirements (e. g. a specific habitat, a particular altitudinal range), as these can better illustrate the processes associated with the geographic patterns of genetic diversity. One example is the study by lgea et al. (2013) that evaluates the post-glacial expansion patterns of the Iberian desman Galemys pyrenaicus, a small semi-aquatic mammal inhabiting clean streams in the northern half of the Iberian Peninsula, which is endangered in most of its geographic range. The authors hypothesize that the strict ecological demands arising from its aquatic habitat, coupled with the effects of the Pleistocene glaciations, led to a marked phylogeographic structure and a genetic pattern associated with the distribution of glacial refugia.

Another topic frequently addressed is the influence of bioclimatic variables on the phylogeographic patterns of various species. Suárez-Atilano et al. (2017) characterized the ecological niches of two lineages of Boa imperator, in order to assess whether certain environmental factors are associated with the divergence and genetic variation between these lineages; interestingly, precipitation and temperature (mainly) were found to be closely related to the distribution and divergence of this reptile's lineages. This work demonstrates that environmental variables may be appropriate predictors of the distribution and divergence of lineages, and that ENM contributes to validating evolutionary patterns from biogeographic and phylogeographic frameworks.

The establishment of some species on their original distribution areas during glacial cycles is known as glacial persistence. Some studies have aimed to measure and explain such persistence. Galbreath et al. (2009) analyze the response of the pika Ochotona princeps to climate changes in the Pleistocene, exploring the influence of changes in elevation on the genetic differentiation and historical 
demography of this alpine specialist. Based on the current phylogeographic structure and the ENM of this lagomorph lineages adapted to low temperatures, the authors have estimated its past and future distribution. Their results suggest that populations of this species increased during the last major glaciation, while the distribution range of some of their lineages declined during the Holocene, making them highly sensitive to climate warming.

The increasing availability of paleoclimatic information has supported phylogeographic and ENM studies for the identification and location of Pleistocene climate refugia, i. e., areas of favorable conditions where species survived during glaciations. For instance, Perktaș et al. (2015) reassessed the historical demography of the Eurasian green woodpecker Picus viridis by producing ENMs based on mitochondrial DNA lineages, which allowed the identification of potential glacial refugia. An excellent proposal on these topics is the one by Gavin et al. (2014) who emphasize the importance of adequately integrating the three major lines of evidence to infer the existence of past refugia: fossil records, ENM, and phylogeographic information.
An essential aspect of phylogeography to understand species divergence and evolutionary patterns (Kalkvik et al. 2012) is to determine the relationship between the diversification of lineages and variations of the ecological niche. Zink et al. (2014) explored the role of niche divergence in the configuration of the distribution ranges of sister species and their speciation process. Their results showed that sister lineages (also called phylogroups) with allopatric distribution share more characteristics of their ancestral niche than those expected by chance, but at the same time, they are distributed in different environments. Hence, they conclude, the latter supports the role of ecology in lineage diversification.

Niche conservatism and divergence. A key issue is to determine whether the ecological niches of species are preserved over time and the evolutionary implications of this trend. This aspect can be evaluated by testing niche conservatism and niche divergence models (Losos 2008; Warren et al. 2008), which allow understanding the relationship between ecological niche and its expression in phylogeographic patterns. However, constructing models to explore
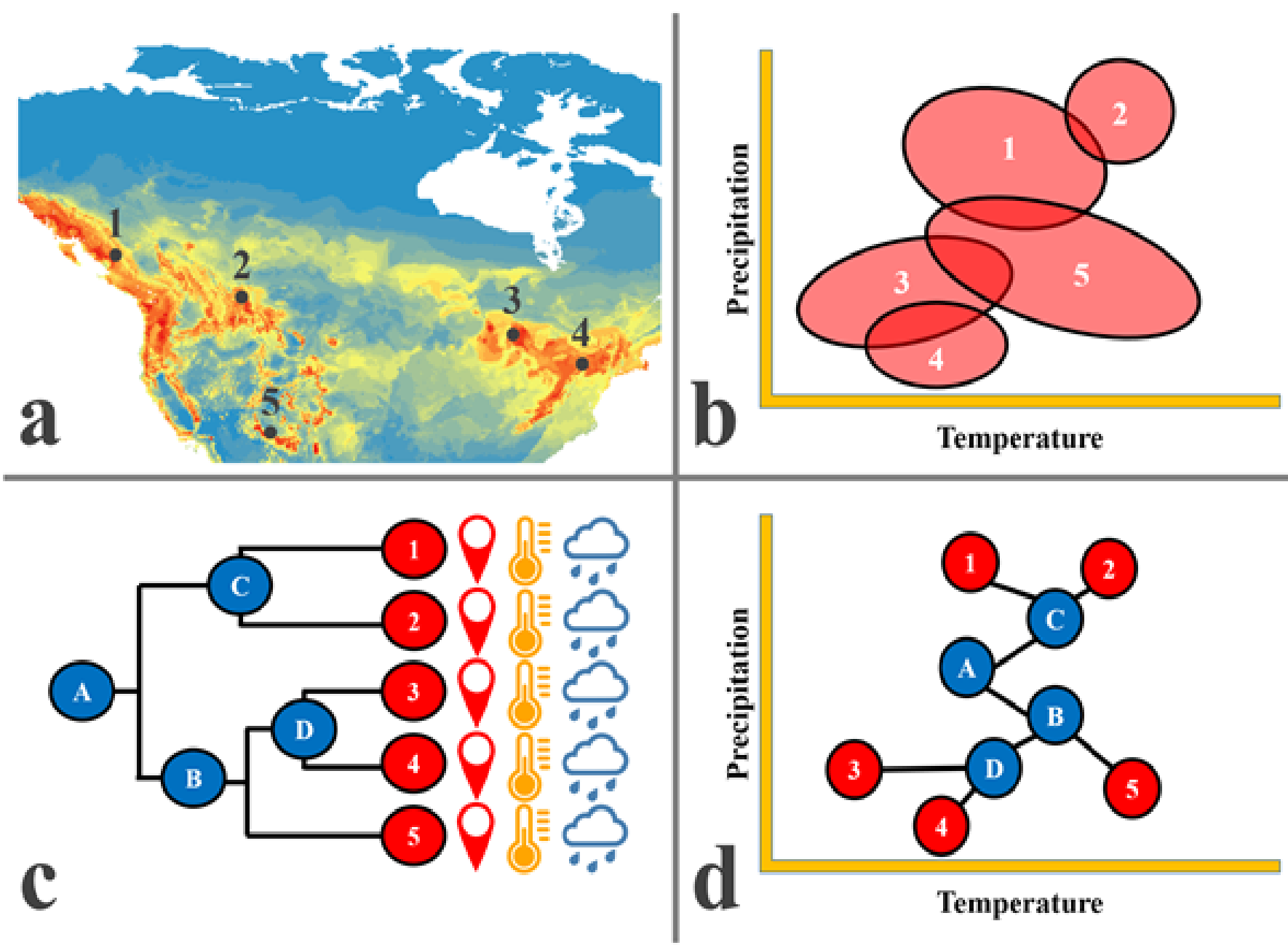

Temperature

Figure 2. Outline of an integrative approach to ecological niche modeling (ENM) and phylogeography. a) ENM generated from presence/absence records in databases and with bioclimatic envelopes; the figure shows sites of capture and DNA collection (1-5) of different populations of the same species (American black bear, Ursus americanus, in this example). b) Ellipsoidal models of multivariate environmental conditions associated with the different populations sampled, from which ecological niches are characterized and measured. c) Phylogenetic relationships between the lineages obtained; the environmental values for each lineage can be derived from the respective coordinates. d) Example of phyloclimaticspatial integration, where ancestral (environmental) states can be reconstructed from the relationships between lineages, assuming a Brownian evolutionary model, which facilitates summarizing the vast amount of evolutionary and climatic information. 
these issues pose conceptual and methodological challenges, mostly because many of the variables involved in evolutionary processes, such as biotic interactions, cannot be included in ENM. There is, however, significant progress in the generation of models which currently serve as analytical baselines and which, in the future, could be supplemented by integrating phylogeographic methods. Rolland et al. (2018) integrated fossil and neontological data for 11,465 species of birds, mammals, reptiles, and amphibians to compare the evolution of climatic niches; these authors found that niches evolve at a significantly faster rate in endotherm vs. ectotherm organisms. Another example is the study of Velasco et al. (2018), who evaluated the effect of climate on species richness gradients of lizards of the genus Anolis, demonstrating a significant relationship at the regional level between climate and number of species, although with no evidence of niche conservatism.

On the other hand, a study that evaluates niche divergence and phylogeographic patterns is that of Ashrafzadeh et al. (2018), who tested the effect of isolation by distance and environment on the genetic structure of the Iranian brown bear (Ursus arctos), based on random regression methods of multiple matrices and niche models at the population level. They found a strong population structure (differentiation) and a low percent of overlap between population niches as a result of niche divergence.

From niche to fact: criticism, complexities, and progress. The adequate development of phylogeographic studies involves important considerations, such as the need to use multiple molecular markers; sufficient sampling coverage according to the scale of the study (local, regional, global); and analytical methods, especially given the analytical challenges that arise when determining divergence patterns and driving factors (e. g., mutation rates, ancestral population sizes, generation times, migration). Also, the dating of divergence events demands considering that different sources of information (fossils, genes) can produce different dates for the same event, an outcome that warrants due consideration (Beaumont 2010; Gutiérrez-García and Vázquez-Domínguez 2011).

ENM and the set of techniques associated to it, even as an approach with vast potential for synergy with phylogeography and other fields of study, is not exempt from debate and criticism, mainly due to the need of more robust theoretical and methodological bases to improve its procedures and interpretation of results (Peterson 2011). According to Varela et al. (2011), some of the most debated methodological and conceptual issues are: 1 ) biases and scarcity of data for many of the current and fossil species; 2) higher certainty when determining the influence and biological relevance of environmental variables used; 3) ability to produce reliable representations of the biota's geographic distribution with methods based on presence-absence data. Also discussed is the current lack of robust and comparable evaluation and validation methods for the different algorithms used to estimate ENMs (Raxworthy et al. 2007;
Lobo et al. 2008), the uncertainty associated with paleoclimate reconstructions commonly used in ENM (Varela et al. (2011)), and the effect of spatial and temporal autocorrelation (de Oliveira et al. 2014). Also debated are the impact of other aspects related to the functioning and statistical procedures of algorithms (Terrible et al. 2010; Peterson et al. 2015), the resolution and quality of bioclimatic envelopes (Varela et al. 2015), and the risks associated with spatial autocorrelation in the analysis of the geographic distribution of lineages (de Oliveira et al. 2014; Warren et al. 2014).

In particular, biases in presence records used to construct paleodistribution models limit the reliability of inferences derived without rigorous use of available fossil records and alternative sources of paleobiogeographic information (Davis et al. 2014). In paleoecology, a non-analogous climate is defined as the combination of past environmental conditions that no longer exist today (Williams and Jackson 2007), which has important implications when potential distribution models are projected to the past and future. Worth et al. (2014) suggest using different climate circulation models and sources of paleoclimatic information to establish biological criteria for a more rigorous selection of paleodistribution projections.

The criticism and debate are not limited to the technical implementation of ENM but also relate to fundamental theoretical aspects, particularly niche conservatism (Peterson 2011; Pyron et al. 2015). The debate focuses not only on the mechanisms required for niche conservatism and its relationship with the evolution of lineages but also on the evolution rate of ecological niches. Thus, some authors argue that ecological niches are characterized by a general high evolution rate, while others contend otherwise; however, no study has theoretically tested the comparability of the different case studies. Therefore, in line with other authors (Svenning et al. 2011; Alvarado-Serrano and Knowles 2014), we highlight the importance of considering the methodological limitations of ENM when applied to phylogeographic studies, particularly the difficulty of including the biotic and behavioral traits of the different species. Additionally, the results should be interpreted according to theoretical bases; spatial and temporal uncertainties associated with bioclimatic envelopes, and species presence records should be rigorously considered.

Fundamental niche and realized niche: shadows in the night. The integration of ENM to phylogeography has contributed to addressing key questions about the distribution and evolution of species, as well as regarding the methods and approaches used to conduct these assessments (Alvarado-Serrano and Knowles 2014). However, although significant progress has been made, theoretical and technical challenges still remain that should be overcome. The first is related to a central aspect within ecological niche theory: certainty about what is being measured. The fundamental niche is the multivariate range of physiological tolerances of a species (e. g., temperature or humidity), within which positive population growth rates occur (Hutchinson 1957; Pul- 
liam 2000; Peterson et al. 2011; Soberón and Peterson 2011); for its part, the realized niche is the existing and available subset of the fundamental niche that is actually accessible for a species, either naturally or as a result of anthropogenic factors (Pearman and Guisan 2008). However, both niche conservatism and niche evolution are related to changes in the fundamental rather than the realized niche. For this reason, changes in the realized niche do not necessarily reflect evolutionary changes or adjustment to new conditions within the fundamental niche (Soberón and Peterson 2011). Also, accurate estimates of the fundamental niche are hard to derive because explicit information on the physiological tolerance ranges is still missing for most species (Espindola et al. 2019); therefore, caution should be exercised when interpreting the results of ENM regarding phylogeographic patterns.

As regards of the complexities of integrating biological attributes into ENM, given that it uses only information on scenopoetic variables (Hutchinson 1957; Peterson et al. 2011), the inclusion of information about the mobility of species has been suggested, in order to establish the limits of the dispersal of individuals across the landscape, by using probabilistic density functions such as kernels (Worton 1989). Food preferences and other factors governing the distribution of species, including natural enemies and the landscape matrix (i. e., continuous vegetation, mature trees, running water bodies, etc.), may also be used as biological criteria for model selection. On the other hand, the increasing availability of data on the biology of species (physiology, metabolism, behavior, etc.), will allow the future inclusion of this information in ENM to achieve an Eltonian approximation (Espindola et al. 2019).

Likewise, it is possible to integrate information related to biotic interactions such as predation, mutualism, or pollination, which could be incorporated as presence/absence of the different species when modeling the ecological niche of these species. Considering biological and ecological interactions is clearly a key element in the evolution of ENM despite the theoretical and technical challenges involved. Therefore, it is also essential to consider that some biotic interactions operate only at a very fine scale, as in the case of particular behavioral adaptations of individuals, which may be either unimportant or impossible to capture at a broader scale such as the one involved in ENM (Wiens 2011).

In conclusion, the construction of an ENM without considering the biological aspects of the species can lead to misleading interpretations about the environmental limits of its past and current distribution, thus compromising the certainty of predictions for the future. Also, the integration of biotic variables remains challenging due to the information gaps about the particular requirements of each species.

Recent advances and a promising future. Perhaps the most significant step forward in phylogeography is the development of theoretical and mathematical methods to determine divergence patterns and their association with demographic factors and historical changes in population sizes through comparative phylogeography (GutiérrezGarcía and Vázquez-Domínguez 2011). The current possibility of having a large amount of nuclear genetic information, such as SNPs (Single Nucleotide Polymorphisms), compared with the traditional yet more limited cytoplasmic genome (mitochondrial DNA in animals and chloroplast DNA in plants) used in phylogeography, has allowed, among other advances, estimating historical demographic parameters of populations, including population size and gene flow, under a wide variety of evolutionary models (Avise et al. 2016). The integration of phylogeography not only to ENM, but to disciplines such as landscape genetics, which facilitate the direct evaluation of the relationship of environmental, ecological, behavioral, and life-history features of organisms with their respective distribution patterns, is highly promising for advancing the evaluation and interpretation of distribution and biodiversity diversification patterns (Diniz-Filho et al. 2015; Avise et al. 2016).

In addition, ENM is no longer a mere exploratory and visual confirmatory tool of genetic variation patterns in geography; it has gradually become a valuable tool for hypothesis setting and integrated approaches (Chan et al. 2011; Alvarado-Serrano and Knowles 2014). A number of methodological improvements have been proposed as a response to the limitations in the use of ENM in phylogeography (Svenning et al. 2011; Alvarado-Serrano and Knowles 2014; Luna-Aranguré et al. 2019). An excellent example is the contribution of Diniz-Filho et al. (2015), who developed a statistical method to calculate the uncertainty associated with ENM in the analysis of genetic divergence of the legume Dipteryx alata, which strengthen the procedures for selecting models in phylogeographic studies.

On the other hand, given that environmental conditions are variable and that the geographical distribution of species is not static, methods for the quantification of these changes are currently available in both cases, as well as for the resulting genetic variation patterns. A good example is the work of Brown and Knowles (2012), who generated spatial-temporal dynamic models, calibrated with demographic and carrying-capacity information for the American pika Ochotona princeps. In another example, McCormack et al. (2010) show a robust approach for studying allopatric lineages in early speciation stages. These authors compared the ecological niches of five lineages of the birds Aphelocoma ultramarina and Aphelocoma californica to determine whether allopatrically distributed taxa occupy similar niches. Their results point to the opposite, i. e., some of the Aphelocoma species with a partially sympatric distribution show evidence of niche divergence.

Finally, He et al. (2013) used a spatially explicit demographic modeling of genetic differentiation, the results of which suggest that changes in environmental conditions and the distribution from the past to the present significantly contribute to structuring genetic variation. These authors underline the importance of broadening the 
scope of these studies by incorporating aspects of landscape genetics, to assess the landscape factors that govern genetic variation patterns within species.

The availability of data, algorithms, methods, and theory on both phylogeography and ecological niche modeling increases each day, providing more and better tools for integrated use (Alvarado-Serrano and Knowles 2014; Luna-Aranguré et al. 2019). However, understanding the relationship between the distribution of genetic variation of species and the environmental conditions around them remains challenging -- although fascinating --, especially given the errors and biases associated with the data, the relative uncertainty regarding the use of algorithms, the discrepancies in method application and interpretation, and the current gaps in the theory regarding the integration of different information sources. Thus, there are significant challenges that limit progress in the application of ENM to phylogeographic studies, as well as various approaches currently under development that seek to solve them. This demonstrates the huge potential that results from this synergy and the growing possibility that both disciplines become eventually unified. It is also important to note that, although the knowledge derived from ENM has been applied in phylogeography, the opposite has not occurred to integrate phylogeographic knowledge into the ENM field; the theoretical body of phylogeography could be the missing piece for optimum performance in the distribution patterns observed. Thus, a bilateral integration scenario offers the possibility of best practices in the ENM field, the broadening of the hypotheses to test, and a deeper understanding of the evolution of organisms in response to their environmental conditions.

\section{Acknowledgments}

Our gratitude to E. Martínez-Meyer, J. Arroyo-Cabrales, and J. Soberón for the interest and discussions during the development of the research project. We also thank two anonymous reviewers for their insightful comments to a previous version. C. Luna Aranguré thanks the Programa de Posgrado en Ciencias Biológicas de la Universidad Nacional Autónoma de México, and CONACyT (CVU 508602/ Scholarship Reg. 288706) for the economic support provided during his graduate studies; E. Vázquez-Domínguez received economic and logistic support from the Instituto de Ecología. María Elena Sánchez-Salazar translated the manuscript into English.

\section{Literature cited}

Alvarado-Serrano, D. F., And L. L. Knowles. 2014. Ecological niche models in phylogeographic studies: Applications, advances and precautions. Molecular Ecology Resources 14:233-348.

Ashrafzadeh, M. R., R. Khosravi, M. Ahmadi, and M. Kaboli. 2018. Landscape heterogeneity and ecological niche isolation shape the distribution of spatial genetic variation in Iranian brown bears, Ursus arctos (Carnivora: Ursidae). Mammalian Biology 93:64-75.
Avise, J. C. 2000. Phylogeography: The History and Formation of Species. Harvard University Press, Cambridge, U.S.A.

Avise, J. C., B. W. Bowen, and F. J. Ayala. 2016. In the light of evolution X: comparative phylogeography. Proceedings of the National Academy of Sciences 113:7957-7961.

Beaumont, M. A. 2010. Approximate Bayesian computation in evolution and ecology. Annual Review of Ecology. Evolution and Systematics 41:379-406.

Brown, J. L., AND L. L. KNowles. 2012. Spatially explicit models of dynamic histories: examination of the genetic consequences of Pleistocene glaciation and recent climate change on the American Pika. Molecular Ecology 21:3757-3775.

Carstens, B. C., and C. L. Richards. 2007. Integrating coalescent and ecological niche modeling in comparative phylogeography. Evolution 61:1439-1454.

Chan, L. M., J. L. Brown, ANd A. D. Yoder. 2011. Integrating statistical genetic and geospatial methods brings new power to phylogeography. Molecular Phylogenetics and Evolution 59:523-537.

Davis, E. B., J. L. McGuire, ANd J. D. Orcutt. 2014. Ecological niche models of mammalian glacial refugia show consistent bias. Ecography 37:1133-1138.

de Oliveira, G., T. F. Rangel, M. S. Lima-Ribeiro, L. C. Terribile, AND J. A. F. Diniz-Filno. 2014. Evaluating, partitioning, and mapping the spatial autocorrelation component in ecological niche modeling: a new approach based on environmentally equidistant records. Ecography 37:637-647.

DE QUeIROz, K. 2007. S pecies concepts and species delimitation. Systematic Biology 56:879-886.

Diniz-Filho, J. A. F., H. Rodrigues, M. P. D. C. Telles, G. D. Oliveira, L. C. Terribile, T. N. Soares, and J. C. Nabout. 2015. Correlation between genetic diversity and environmental suitability: taking uncertainty from ecological niche models into account. Molecular Ecology Resources 15:1059-1066.

Elton, C. S. 1927. Animal Ecology. Sidgwick and Jackson. London, UK.

Espindola, S., J. L Parra, and E. Vázquez-Domínguez. 2019. Fundamental niche unfilling and potential invasion risk of the slider turtle Trachemys scripta. PeerJ 7:e7923.

Galbreath, K. E., D. J. Hafner, and K. R. Zamudio. 2009. When cold is better: climate-driven elevation shifts yield complex patterns of diversification and demography in an alpine specialist (American Pika, Ochotona princeps). Evolution 63:2848-2863.

Gavin, D. G., M. C. Fitzpatrick, P. F. Gugger, K. D. Heath, F. Rodríguez-Sánchez, S. Z. Dobrowski, and J. L. Blols. 2014. Climate refugia: joint inference from fossil records, species distribution models and phylogeography. New Phytologist 204:37-54.

GrinnelL, J. 1917. The niche-relationships of the California thrasher. Auk 34:427-433.

Gutiérrez-García, T.A., and E. Vázquez-Domínguez. 2011. Comparative phylogeography: designing studies while surviving the process. BioScience 61:857-868.

Hardy, M. E., J. M. Grady, and E. J. Routman. 2002. Intraspecific phylogeography of the slender madtom: the complex evolutionary history of the Central Highlans of United States. Molecular Ecology 11:2393-2403. 
He, Q., D. L.Edwards, and L. L. Knowles. 2013. Integrative testing of how environments from the past to the present shape genetic structure across landscapes. Evolution 67:3386-3402.

Hott, R. D. 2014. Evolution of the Ecological Niche. The Princeton Guide to Evolution. Princeton University Press. Princeton, U.S.A.

Hugall, A., C. Moritz, A. Moussalli, and J. Stanisic. 2002. Reconciling paleodistribution models and comparative phylogeography in the Wet Tropics rainforest land snail Gnarosophia bellendenkerensis (Brazier 1875). Proceedings of the National Academy of Sciences 99:6112-6117.

Hutchinson, G. E. 1957. Concluding Remarks. Cold Spring Harbor Symposia on Quantitative Biology 22:415-427.

Igea, J., P. Aymerich, A. Fernández-González, J. González-Esteban, A. Gómez, R. Alonso, and J. Castresana. 2013. Phylogeography and postglacial expansion of the endangered semi-aquatic mammal Galemys pyrenaicus. BMC Evolutionary Biology 13:115-134.

Kalkvik, H. M., I. J. Stout, T. J. Doonan, and C. L. Parkinson. 2012. Investigating niche and lineage diversification in widely distributed taxa: phylogeography and ecological niche modeling of the Peromyscus maniculatus species group. Ecography 35:54-64.

Kozak, K. H., C. H. Graham, and J. J. Wiens. 2008. Integrating GIS-based environmental data into evolutionary biology. Trends in Ecology and Evolution 23:141-148.

Lobo, J. M., A. Jiménez-Valverde, and R. Real. 2008. AUC: a misleading measure of the performance of predictive distribution models. Global ecology and Biogeography 17:145-151.

Luna-Aranguré, C., J. Soberón, and E. Vázquez-Domínguez. 2019. A tale of four bears: Environmental signal on the phylogeographical patterns within the extant Ursus species. Journal of Biogeography Early vew 10.1111/jbi.13752

Martínez-Méndez, N., O. Mejía, And F. R. M. de la Cruz. 2015. The past, present and future of a lizard: The phylogeography and extinction risk of Sceloporus serrifer (Squamata: Phrynosomatidae) under a global warming scenario. Zoologischer Anzeiger 254:86-98.

McCormack, J. E., A. J. Zellmer, AND L. L. KNowles. 2010. Does niche divergence accompany allopatric divergence in Aphelocoma jays as predicted under ecological speciation?: insights from tests with niche models. Evolution: International Journal of Organic Evolution 64:1231-1244.

Mizerovská, D., V. Nicolas, T. C. Demos, D. Akaibe, M. Colyn, C. DenYs, AND A. Laudisoit. 2019. Genetic variation of the most abundant forest-dwelling rodents in Central Africa (Praomys jacksoni complex): Evidence for Pleistocene refugia in both montane and lowland forests. Journal of Biogeography 46:1466-1478.

Pearman, P. B., A. Guisan, O. Broennimann, and C. F. Randin. 2008. Niche dynamics in space and time. Trends in Ecology and Evolution 23:149-158.

Perktaş, U., H. Gur, and E. Ada. 2015. Historical demography of the Eurasian green woodpecker: integrating phylogeography and ecological niche modelling to test glacial refugia hypothesis. Folia Zoologica 64:284-296.
Peterson, A. T., and N. Vargas. 1993. Ecological diversity in scrub jays, Aphelocoma coerulescens. Pp. 309-317 in Biological Diversity of Mexico: Origins and Distribution (Ramamoorthy T. P., R. Bye, A. Lot, and J. Fa, eds.). Oxford University Press, New York, U.S.A.

Peterson, A. T. 2011. Ecological niche conservatism: A timestructured review of evidence. Journal of Biogeography 38:817-827.

Peterson, A. T., J. Soberón, R. G. Pearson, R. P. Anderson, E. Martínez-Meyer, M. Nakamura, and M. B. Araújo. 2011. Ecological niches and geographic distributions. Princeton University Press, New Jersey, U.S.A.

Peterson, A. T., M. Papeș, And J. Soberón. 2015. Mechanistic and correlative models of ecological niches. European Journal of Ecology 1:28-38.

Pulliam, H. R. 2000. On the relationship between niche and distribution. Ecology letters 3:349-361.

Pyron, R. A., G.C. Costa, M. A. Patten, and F. T. Burbrink. 2015. Phylogenetic niche conservatism and the evolutionary basis of ecological speciation. Biological Reviews 90:1248-1262.

Rangel, T. F., N. R. Edwards, P. B. Holden, J. A. F. Diniz-Filho, W. D. Gosling, M. T. P. Coelho, And R. K. Colwell. 2018. Modeling the ecology and evolution of biodiversity: Biogeographical cradles, museums, and graves. Science 361:eaar5452.

Raxworthy, C. J., C. M. Ingram, N. Rabibisoa, and R. G. Pearson. 2007. Applications of ecological niche modeling for species delimitation: a review and empirical evaluation using day geckos (Phelsuma) from Madagascar. Systematic Biology 56:907-923.

Rolland, J., D. Silvestro, D. Schluter, A. Guisan, O. Broennimann, and N. Salamin. 2018. The impact of endothermy on the climatic niche evolution and the distribution of vertebrate diversity. Nature Ecology and Evolution 2:459-464.

Rosauer, D. F., R. A. Catullo, J. VanDerWal, A. Moussalli, and C. MoRITZ. 2015. Lineage range estimation method reveals finescale endemism linked to Pleistocene stability in Australian rainforest herpetofauna. PloS One 10:e0126274.

Smith, A. B., W. Godsoe, F. Rodríguez-Sánchez, H. H. Wang, AND D. WARREN. 2018. Niche estimation above and below the species level. Trends in Ecology and Evolution 34:260-273.

Soberón, J. 2007. Grinnellian and Eltonian niches and geographic distributions of species. Ecology Letters 10:11151123.

Soberón, J., And A. T. Peterson. 2005. Interpretation of models of fundamental ecological niches and species' distributional areas. Biodiversity Informatics 2:1-10.

Soberón, J., and A. T. Peterson. 2011. Ecological niche shifts and environmental space anisotropy: a cautionary note. Revista Mexicana de Biodiversidad 82:1348-1355.

Suárez-Atilano, M., O. Rojas-Soto, J. L. Parra, and E. VázquezDomínguez. 2017. The role of the environment on the genetic divergence between two Boa imperator lineages. Journal of Biogeography 44:2045-2056.

Svenning, J. C., C. Fløjgaard, K. A. Marske, D. Nógues-Bravo, And S. Normand. 2011. Applications of species distribution modeling to paleobiology. Quaternary Science Reviews 30:2930-2947. 
Terribile, L. C., AND J. A. F. Diniz-Filho. 2010. How many studies are necessary to compare niche-based models for geographic distributions? Inductive reasoning may fail at the end. Brazilian Journal of Biology 70:263-269.

Varela, S., J. M. Lobo, and J. Hortal. 2011. Using species distribution models in paleobiogeography: a matter of data, predictors and concepts. Palaeogeography, Palaeoclimatology, Palaeoecology 310:451-463.

Varela, S., M. S. Lima-Ribeiro, and L. C. Terribile. 2015. A short guide to the climatic variables of the Last Glacial Maximum for biogeographers. PloS One 10:e0129037.

Vázquez-Domínguez, E. 2007. Filogeografía y vertebrados. Pp. 441-466 in La ecología molecular de plantas y animales. (Eguiarte L., V. Souza, and X. Aguirre, eds.). INE. Ciudad de México, México.

Velasco, J. A., F. Villalobos, J. A. Diniz-Filho, A. C. Algar, O. Flores-Villela, G. Köhler, and E. Martínez-Meyer. 2018. Climatic and evolutionary factors shaping geographical gradients of species richness in Anolis lizards. Biological Journal of the Linnean Society 123:615-627.

Warren, D. L., R. E. Glor, ANd M. Turelli. 2008. Environmental niche equivalency versus conservatism: quantitative approaches to niche evolution. Evolution 62:2868-2883.

Warren, D. L., M. Cardillo, D. F. Rosauer, and D. I. Bolnick. 2014. Mistaking geography for biology: inferring processes from species distributions. Trends in Ecology and Evolution 29:572-580.

Wiens, J. J. 2011. The niche, biogeography and species interactions. Philosophical Transactions of the Royal Society B: Biological Sciences 366:2336-2350.

Wiens, J. J., and C. H. Graham. 2005. Niche conservatism: integrating evolution, ecology, and conservation biology. Annual Review of Ecology, Evolution and Systematics 36:519539.

Williams, J. W., and S. T. Jackson. 2007. Novel climates, noanalog communities, and ecological surprises. Frontiers in Ecology and the Environment 5:475-482.

Worth, J. R., G. J. Williamson, S. Sakaguchi, P. G. Nevill, and G. J. JORDAN. 2014. Environmental niche modelling fails to predict Last Glacial Maximum refugia: niche shifts, microrefugia or incorrect palaeoclimate estimates? Global Ecology and Biogeography 23:1186-1197.

Worton, B. J. 1989. Kernel methods for estimating the utilization distribution in home-range studies. Ecology 70:164-168.

ZiNk, R. M. 2014. Homage to Hutchinson, and the role of ecology in lineage divergence and speciation. Journal of Biogeography 41:999-1006.

Associated editor: Guillermo D'Elía

Submitted: June 6, 2019; Reviewed: August 24, 2019;

Accepted: November 11, 2019; Published on line:December 17, 2019. 
56 THERYA Vol. 11 (1): 47-55 